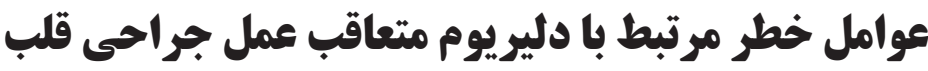

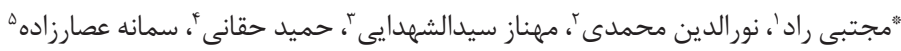

جكيده

مقدمه: دليريوم سندرومى است كه با اختلال هوشيارى و تغيير در شناخت مشخص مىشود كه درصد بالايى از بيماران

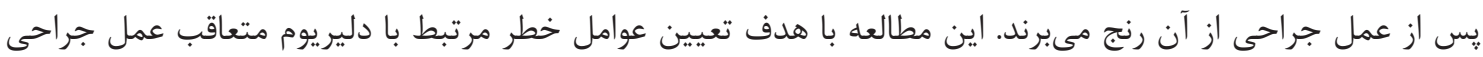

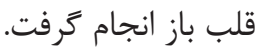
مواد و روشها: يزوهش حاضر يك مطالعه توصيفى-مقطعى بود كه در سال بM ا در بيمارستانهاى شهيد رجايى و محب انجام شد. تعداد شركتكنندًان در اين مطالعه • • نفر بودند. در اين يزوهش كليه بيماران بسترى در بخش مراقبت ويزه متعاقب عمل جراحى قلب باز مورد مطالعه قرار كرفتند. عوامل خطر مورد بررسى شامل اطلاعات دموكر افيك

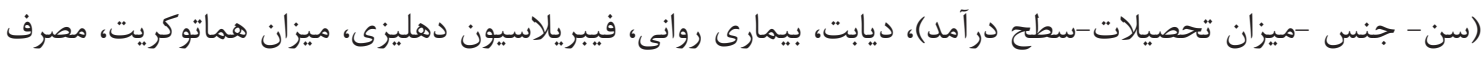
سيكار و مواد مخدر، يرفشارى خون، سابقه سكتهى مغزى و عمل جراحى مجدد، كسر تخليهاى بطن جِ، استفاده يا

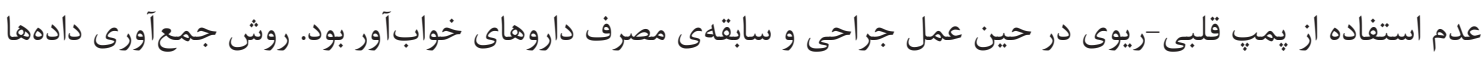

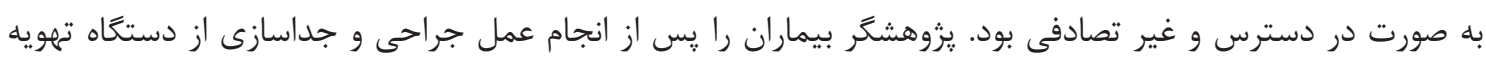

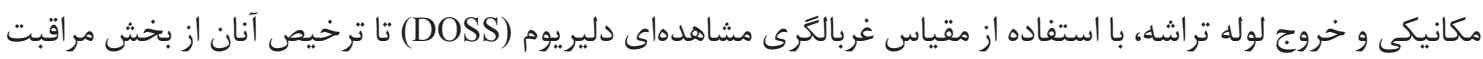

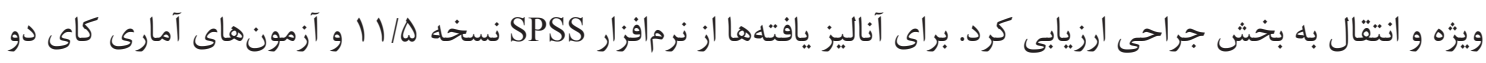
و تست دقيق فيشر استفاده شد. يافتهها: در اين مطالعه ميزان بروز دليريوم بr درصد به دست آمد. از بين متغيرهاى مورد بررسى در اين مطالعه سطح

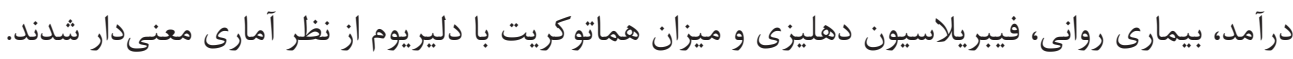
بحث و نتيجهَيرى: با توجه به بروز دليريوم بعد از جراحى، شناسايى و غربالكرى دليريوم بعد از عمل جراحى قلب باز از اهميت بالايى برخوردار مىباشد. همجنين با نگاه به مشخصات فردى و عوامل مرتبط با بروز دليريوم شناسايى شده در

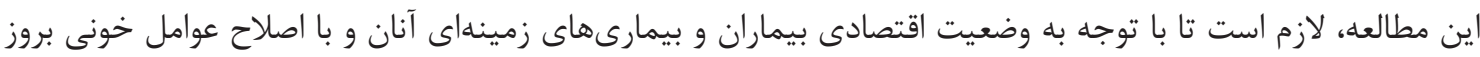
دليريوم بعد از عمل جراحى را كاهش داد. كلمات كليدى: جراحى قلب باز، دليريوم، عوامل خطر. 
بالا، فيبر يلاسيون دهليزى، اوره و كراتنين بالاى خون و سابقهى

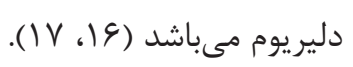

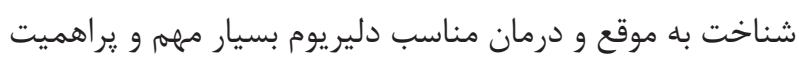

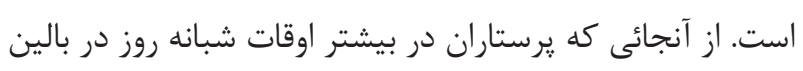
بيمار حضور دارند و بروز دليريوم هم نوسان دار مىباشد، مى توانند نقش كليدى در كشف و شناسايى به موقع بروز علائم دليريوم از

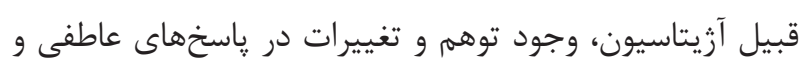

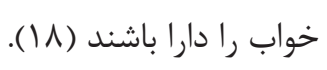

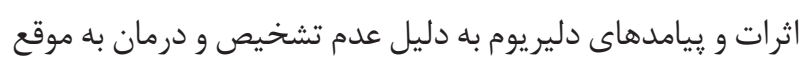

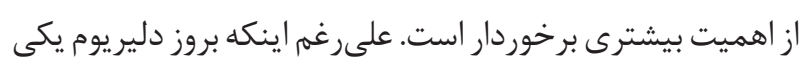

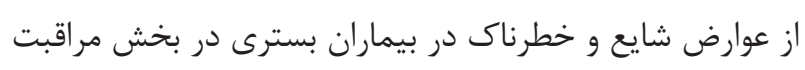

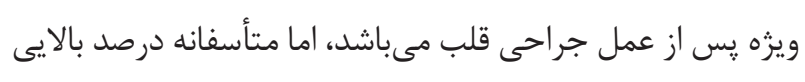

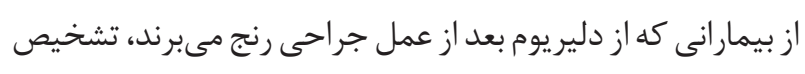

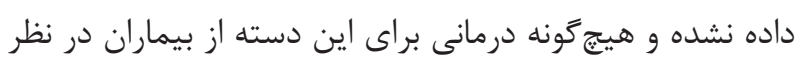

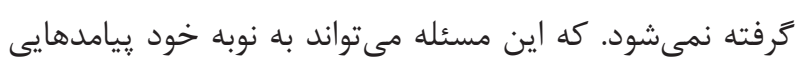

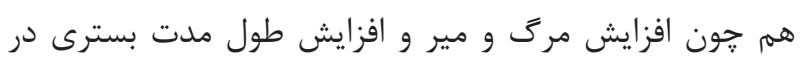

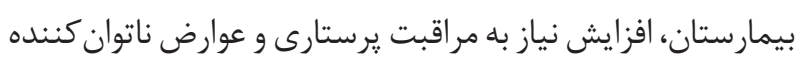

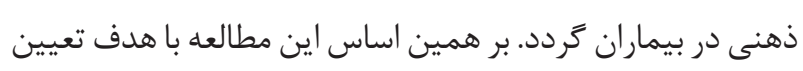

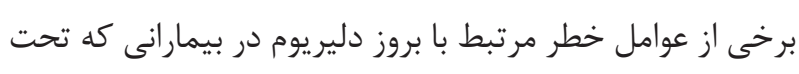
عمل جراحى قلب باز قرار گَرفتهاند، انجام گَرديد.

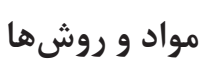

اين مطالعه يك مطالعه توصيفى -مقطعى بود. محيط اين يزوهش

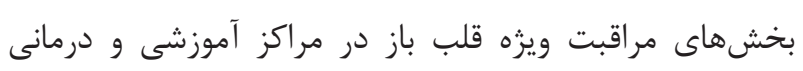
بيمارستانهاى شهيد رجايى و محب در شهر تهران در در سال MNM

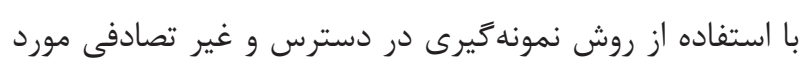

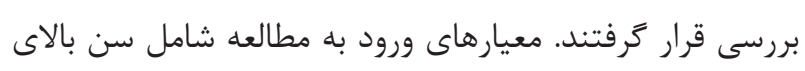

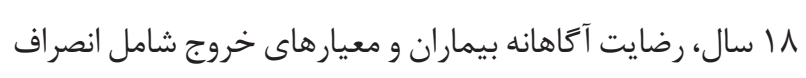
بيمار از مطالعه، وجود ناشنوايى و عدم تكلم در رياسخ به سؤالات بـات

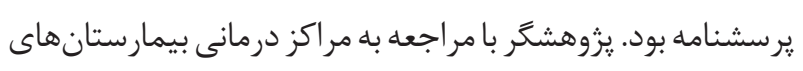

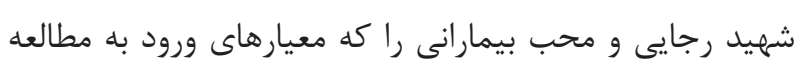

اختلال موقعيت سنجى، شروع سريع جند ساعته تا هند روزه،

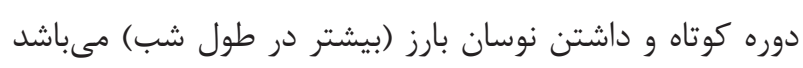

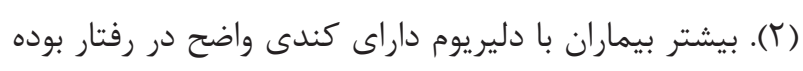
و حالتهاى كيجى از خود نشان مى دهند. همجنين اين بيماران بدون توجه بوده و همكارى لازم با يرستاران را ندارند (؟).

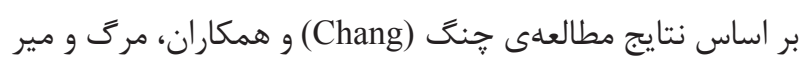
در بيمار انى كه در طول مدت بسترى خود در بيمارستان دليريوم را

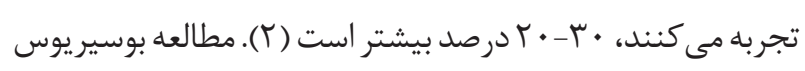

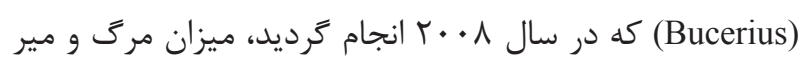

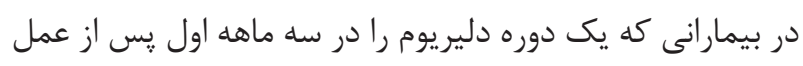

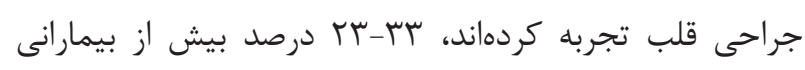

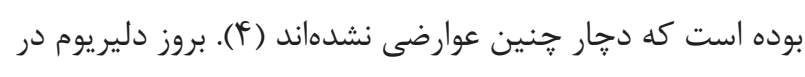

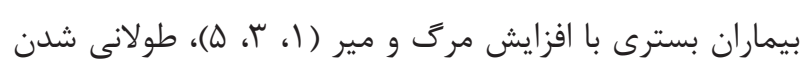

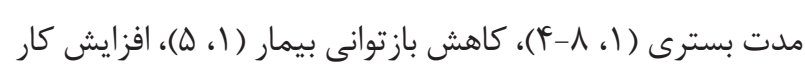

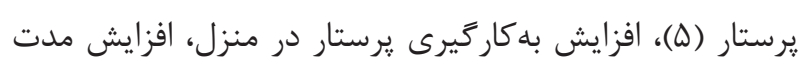

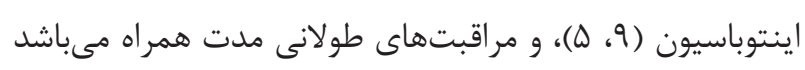

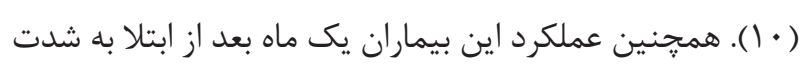

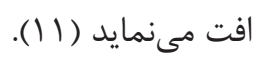

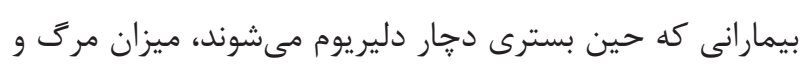

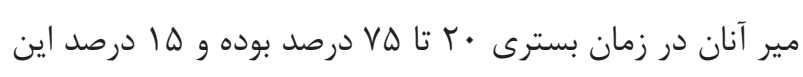

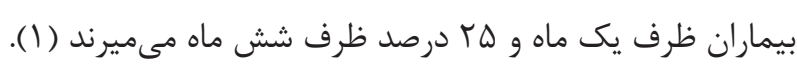

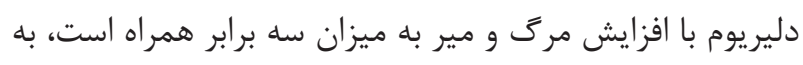

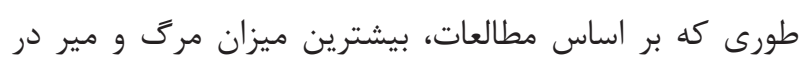

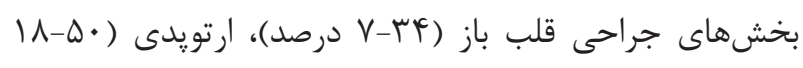

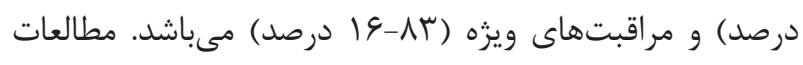

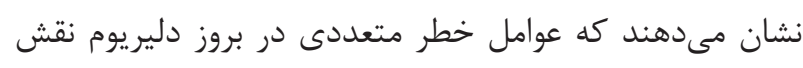

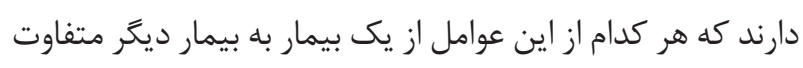

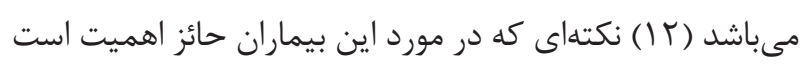

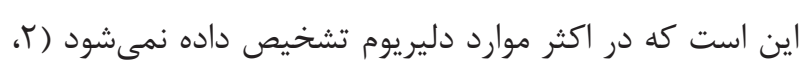

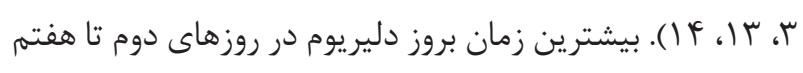
بعد از عمل جراحى قلب باز مىباشد (هان ).

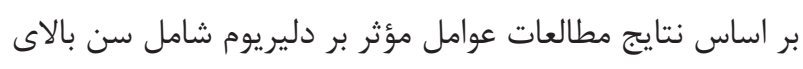

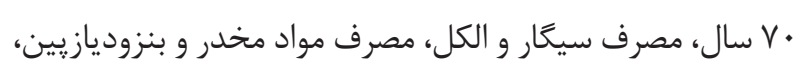

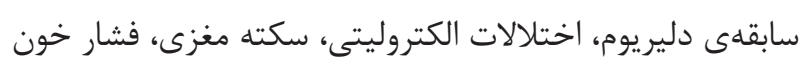


كرفتند. لازم به ذكر است كه اين · ب نفر جزء نمونهها محسوب

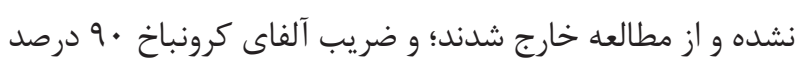
به دست آمد. حجم نمونه براساس فرمول زير مىباشد.

$$
n=\frac{\mathrm{z}^{r} 1-\frac{\alpha}{r} \times \mathrm{p} \times \mathrm{r}}{\mathrm{d}^{r}}
$$

براى هر بيمار يرسشنامه اطلاعات جمعيت شناختى و جكليست عوامل خطر مرتبط با بروز دليريوم بعد از عمل تكميل خرديد. بعد از جمعآورى برسشنامهها به منظور توصيف نمونهها و ميزان

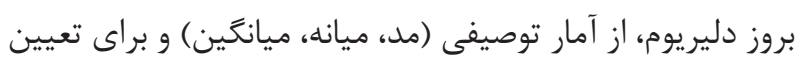

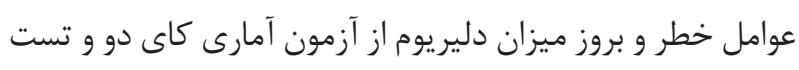
دقيق فيشر استفاده شد.

يافتهها در اين يزوهش • • ب نفر از افراد واجد شرايط مورد مطالعه قرار

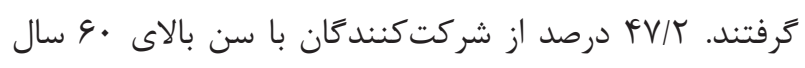

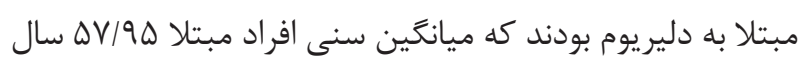

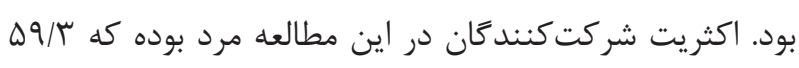

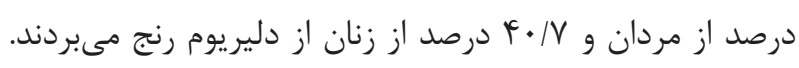
بيشتر شركت كنند

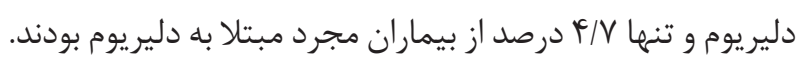
از نظر سطح تحصيلات، بيشتر شركت كنند

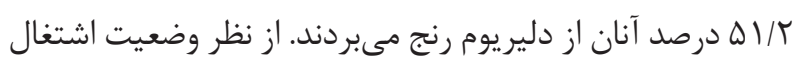

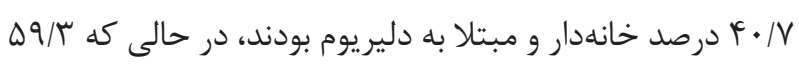

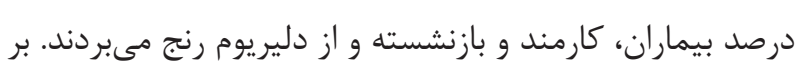

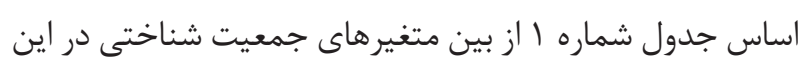

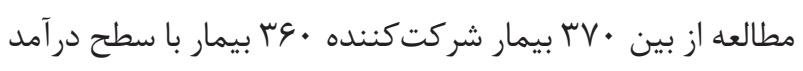

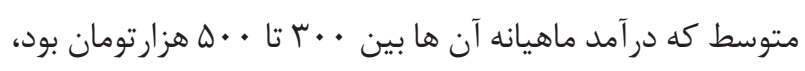
F F نفر آنها مبتلا به دليريوم بودند.

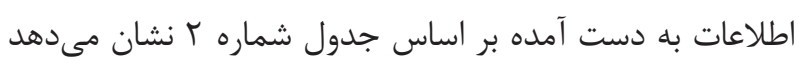

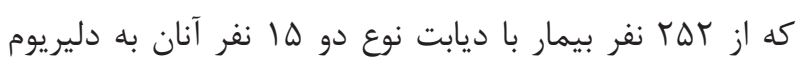

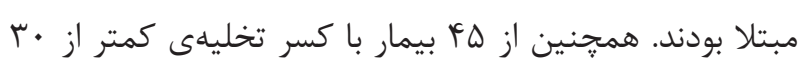

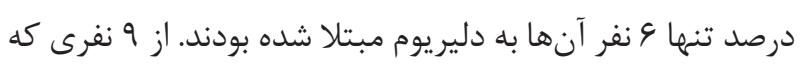

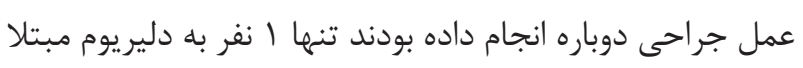

اخذ رضايت آكاهانه از شركت كنند

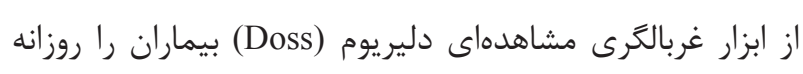
در بخش مراقبتهاى ويزه قلب باز بعد از در آوردن لوله تراشه دئه

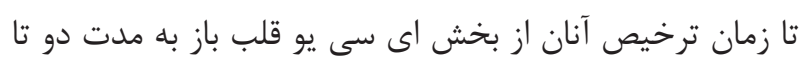

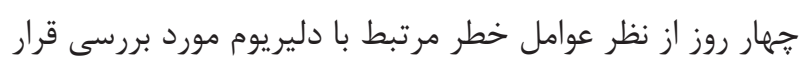

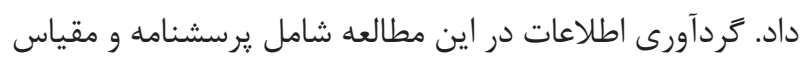
مشاهدهاى Doss بود. بخش اول يرسشنامه مربوط به اطلاعات

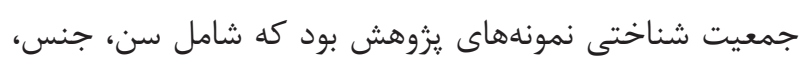
وضعيت تأهل، سطح تحصيلات، سطح در آمد و وضعيت اشتغال بود.

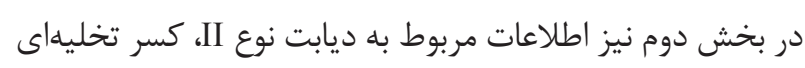

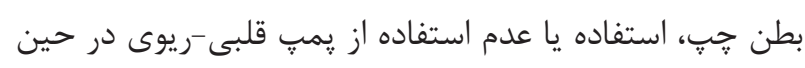
عمل جراحى، انجام عمل جراحى مجدد، سابقه مصرف سيكار،

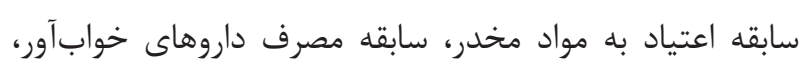

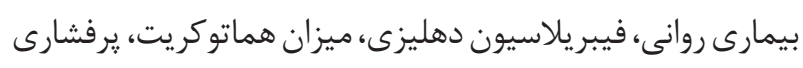

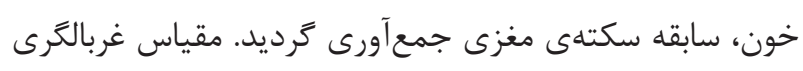

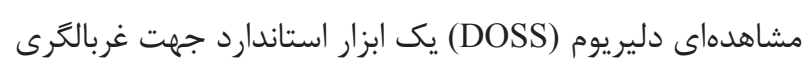

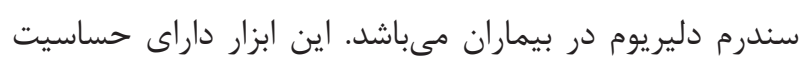

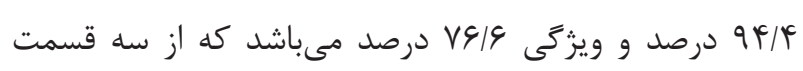

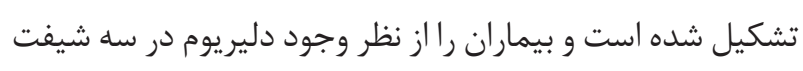
صبح، عصر و شب مورد سنجش قرار مى داد نمرهى كل اين ابزار

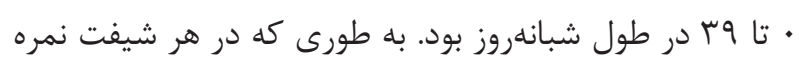

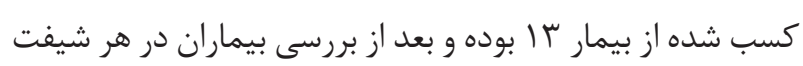

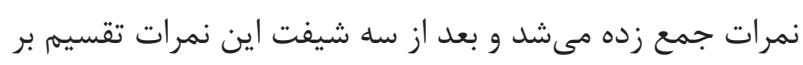

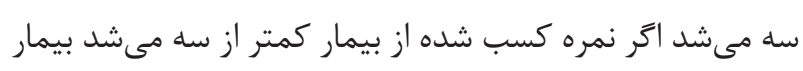

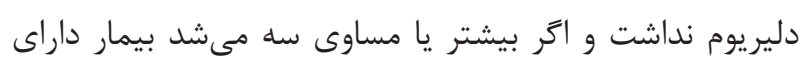

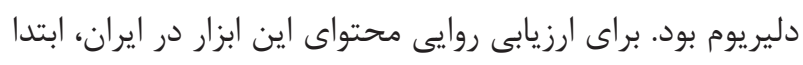

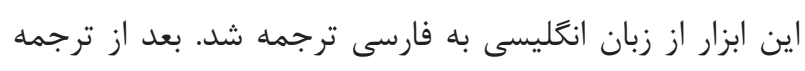

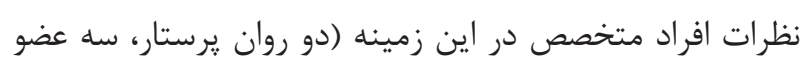
هيئتعلمى مراقبت ويزه، يك نفر متخصص بيهوشى و دو نفر از

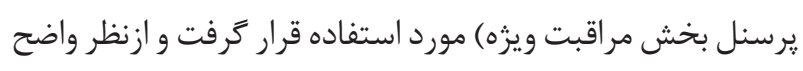

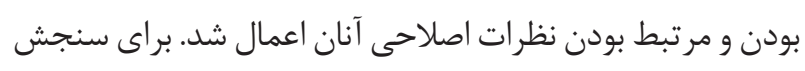

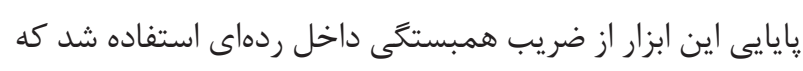

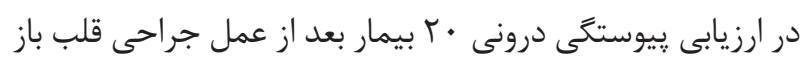

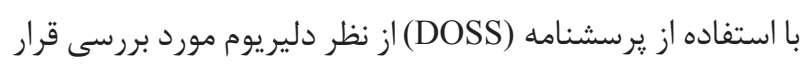


جدول ا- رابطه بين مشخصات دموكر افيك با ميزان بروز دلير يوم بعد از عمل جراحى قلب باز

\begin{tabular}{|c|c|c|c|c|}
\hline ارزش p & مبتلا به دليريوم & $\begin{array}{l}\text { تعداد } \\
\text { N }=\text {. }\end{array}$ & متغير هاى دموكر افيك & \\
\hline \multirow{2}{*}{$\mathrm{P}=\cdot / \cdot \Delta$} & $i d$ & 194 & زير ·9 سال & \multirow{2}{*}{ سن } \\
\hline & il & IVV & بالاى •9 سال & \\
\hline \multirow{2}{*}{$\mathrm{P}=\cdot / \wedge$} & $r \wedge$ & וזr & 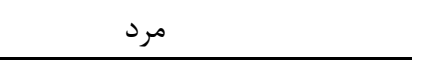 & \multirow{2}{*}{ جنس } \\
\hline & 11 & 119 & زن & \\
\hline \multirow{4}{*}{$\mathrm{P}=\cdot / \mathrm{V}$} & re & 19. & 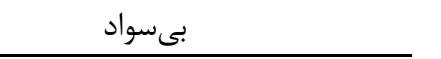 & \multirow{4}{*}{ تحصيلات } \\
\hline & Ir & תו & سيكل تا دييلم & \\
\hline & $\Delta$ & pq & دييلهم & \\
\hline & f & ऍᄉ & دانشعاهى & \\
\hline \multirow{3}{*}{$\mathrm{P}=\cdot / \cdot \mathrm{r}$} & r & $\Lambda$ & زير ..r هزار تومان & \multirow{3}{*}{ سطح درآمد } \\
\hline & Fr & rG. & 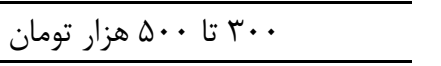 & \\
\hline & 1 & $r$ & بالاى • ••ه هزار تومان & \\
\hline \multirow{3}{*}{$\mathrm{P}=\cdot / 9$} & 19 & Ir & خانهدار & \multirow{3}{*}{ وضعيت شاغل } \\
\hline & 19 & $1 \cdot 1$ & كارمند & \\
\hline & 14 & ITF & بازنشسته & \\
\hline \multirow{3}{*}{$\mathrm{P}=\bullet / \Delta$} & r & IV & مجرد & \multirow{3}{*}{ وضعيت تأهل } \\
\hline & Fr & rar & متأهل & \\
\hline & . & . & مطلقه & \\
\hline
\end{tabular}

آن كاهش هوشيارى است كه معمولاً همراه با اختلال كلى در اعمال شناختى ظاهر مى گردد. در ارتباط با مشخصات جمعيت شناختى تجزيه و تحليل آمارى نشان داد كه بين سن و بروز دلير يوم رابطهى معنى دارى وجود نداشت. در مطالعات بوسيريوس

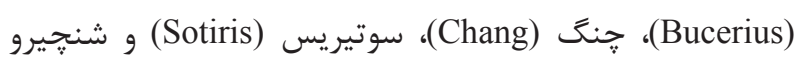
سن به عنوان يكى از عوامل مههم در بروز دليريوم (Shinichiro) ذكر شده و نتايج مطالعات فوق رابطه آمارى معنى دارى را ميان سن و دليريوم نشان دادند. همجنين مطالعه اينويى (Inouye) و

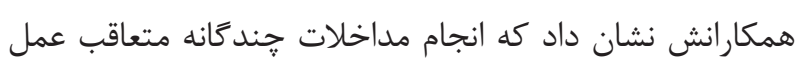
جراحى مىتواند در كاهش بروز دليريوم نقش جشمخيرى داشته باشد. در مطالعه اينويى كه بيماران با سن · V سال و بيشتر شركت داشتند، نشان داده شد كه بروز دليريوم با انجام مداخلات جند كَانه شامل استفاده از يروتكلهاى مخصوص مانند كاهش بىحركتى، خواب كافى، برطرف كردن نقايص شنوايى و ديدارى و همجنين حفظ هيدراسيون كافى، كاهش آمارى معنى دارى داشت (Tr). از نظر يروهشگر با توجه به اينكه اكثر شركت كنندگان در اين اهنئ
شده بود. در اين مطالعه \&1 نفر سيعارى بودند و 11 نفر آنها

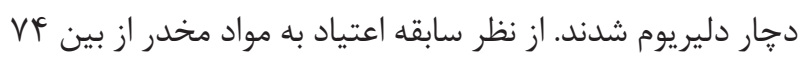
فرد مصرف كنندهى مواد مخدر تنها • ا نفر آنها داراى دليريوم بودند. سعا نفر از شركت كنندگان داراى فشار خون بالا بودند كه از بين متغيرهاى مرتبط با دليريوم در اين مطالعه بيشترين بيمارى زمينهاى مشاهده شده و كمترين بيمارى زمينهاى سكته مغزى بود؛ و از بين • TV شركت كننده تنها 9 بيمار نياز به عمل جراحى مجدد يیدا كرده بودند. همجنين در جدول ب نشان داده شده است كه تفاوت معنادارى بين اين متغيرها و بروز دليريوم وجود دارد و از بين متغيرهاى مورد بررسى بيشتر شركت كنند درصد برخوردار بودند

\section{بحث و نتيجه كيرى}

دليريوم از جمله اختلالات شناختى مىباشد كه با اختلال در هوشيارى و تخريب شناختى همراه مىباشد و علامت مشخصه 
جدول r- رابطه بين عوامل خطر با ميزان بروز دليريوم بعد از عمل جراحى قلب باز

\begin{tabular}{|c|c|c|c|c|}
\hline ارزش & مبتلا به دلير يوم & 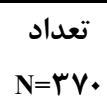 & 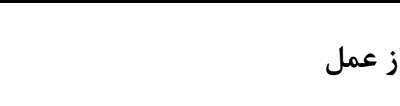 & \\
\hline \multirow{2}{*}{$\mathrm{P}=\cdot / 9$} & 10 & raT & 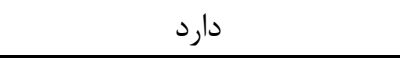 & \multirow{2}{*}{ سابقه ديابت نوع II } \\
\hline & 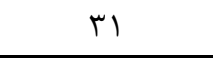 & 111 & 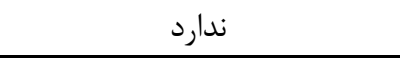 & \\
\hline \multirow{2}{*}{$\mathrm{P}=\cdot \mid \wedge$} & 4 & $r \Delta$ & كمتر از •r درصد & \multirow{2}{*}{ كسر تخليهاى بطن جֶ } \\
\hline & f. & rta & كسر تخليهاى بيشتر از • ب درصد & \\
\hline \multirow{2}{*}{$\mathrm{P}=\cdot 19$} & er & MF & دارد & \multirow{2}{*}{ استفاده از پِّ قلبى ـريوى } \\
\hline & i & tr & 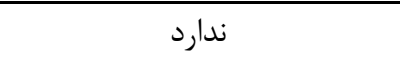 & \\
\hline \multirow{2}{*}{$\mathrm{P}=\cdot / 9$} & 1 & 9 & دارد & \multirow{2}{*}{ عمل جراحى دوباره } \\
\hline & id & (1) & 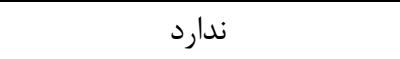 & \\
\hline \multirow{2}{*}{$\mathrm{P}=\cdot / 9$} & 11 & 19 & دارد & \multirow{2}{*}{ سابقه مصرف سيگار } \\
\hline & ra & rAF & 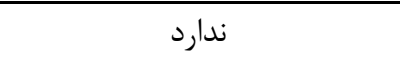 & \\
\hline \multirow{2}{*}{$\mathrm{P}=\cdot / \mathrm{V}$} & 1. & $V F$ & دارد & \multirow{2}{*}{ سابقه اعتياد به مواد مخدر } \\
\hline & re & rqq & 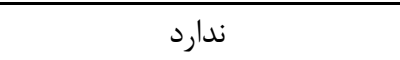 & \\
\hline \multirow{2}{*}{$\mathrm{P}=\cdot / \mathbb{F}$} & r & 19 & بلى & \multirow{2}{*}{ سابقه مصرف داروى خوابآور } \\
\hline & س & raf & خير & \\
\hline \multirow{2}{*}{$\mathrm{P}=\cdot / \Gamma$} & IV & س & دارد & \multirow{2}{*}{ يرفشارى خون } \\
\hline & $r q$ & $r \cdot V$ & 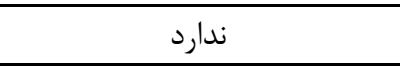 & \\
\hline \multirow{2}{*}{$\mathrm{P}=\cdot / \mathrm{T}$} & - & $\Lambda$ & 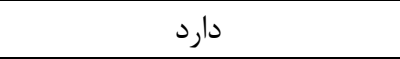 & \multirow{2}{*}{ سكته مغزى } \\
\hline & is & 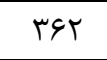 & 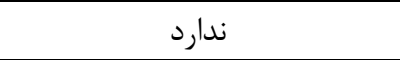 & \\
\hline
\end{tabular}

جدول بـ- رابطه بين عوامل خطر با ميزان بروز دلير يوم بعد از عمل جراحى قلب باز

\begin{tabular}{|c|c|c|c|c|}
\hline ارزش p & مبتلا به دليريوم & $\begin{array}{l}\text { تعداد } \\
\text { N }=\text {. }\end{array}$ & متغيرهاى بعد از عمل & \\
\hline \multirow{2}{*}{$\mathrm{P}=\cdot / \cdots$} & $\Delta$ & 1 . & دارد & \multirow{2}{*}{ سابقهى بيمارى روانى } \\
\hline & (1) & re. & 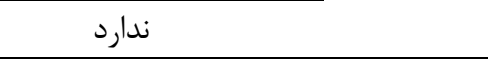 & \\
\hline \multirow{2}{*}{$\mathrm{P}=\cdot / \cdot \cdot \varphi$} & 1 & 4. & دارد & \multirow{2}{*}{ فيبريلاسيون دهليزى } \\
\hline & id & ו. & 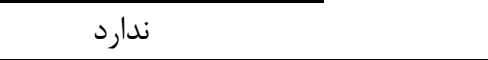 & \\
\hline \multirow{2}{*}{$\mathrm{P}=\cdot / \cdot r$} & ret & 111 & كمتر از درصد • & \multirow{2}{*}{ ميزان هماتوكريت } \\
\hline & If & 119 & بيشتر از درصد ·r & \\
\hline
\end{tabular}

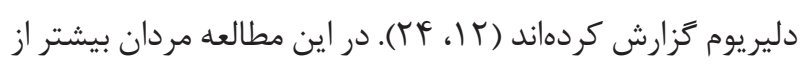
زنان مستعد ابتلا به دليريوم بودند كه احتمالاً اين نسبت مربوط به تعداد شركت كنندكان مرد در اين مطالعه مىباشد. با توجه به اينكه اكثر شركت كنند

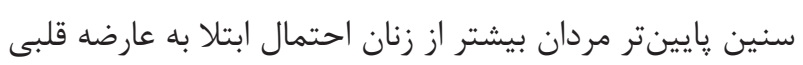

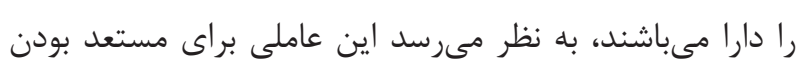

مطالعه زير •ع سال سن داشتند و بر اساس مطالعات نشان داده شده كه بيشتر بيماران مبتلا به دليريوم بالاى هو سال سن دارند

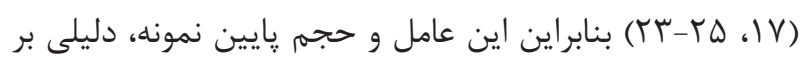
معنادار نشدن اين متغير با بروز دليريوم مىتواند باشد. از نظر آمارى ارتباط معنادارى بين جنسيت و بروز دلير يوم وجود نداشت. در مطالعات مختلف برخى مردان و برخى زنان را مستعد براى بروز 
عمل جراحى قلب ندارد. اين يافته همسو با يافتههاى مطالعه

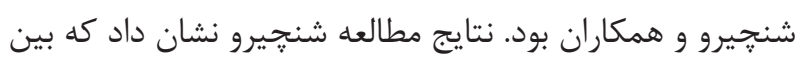

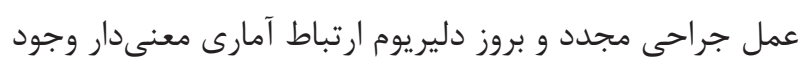

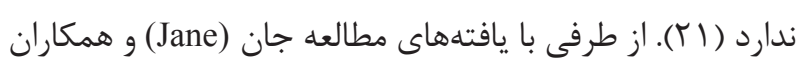
مغايرت داشت. بهطورى كه نتايج مطالعه جان حاكى از ارتباط آمارى معنى دار ميان عمل جراحى دوباره و بروز دليريوم بود (ع) بهائ.

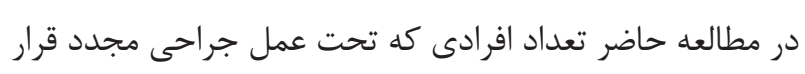

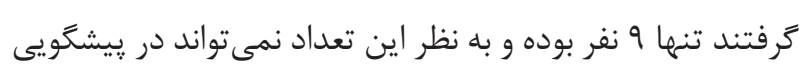
بروز دليريوم با اين متغير كافى باشد. از طرف ديخر، ماهيت

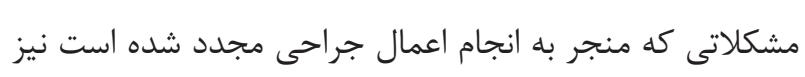

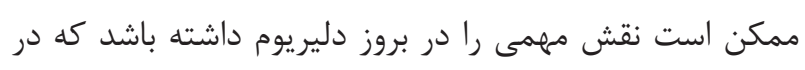

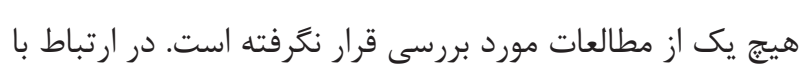

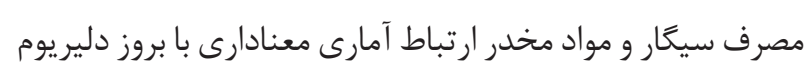

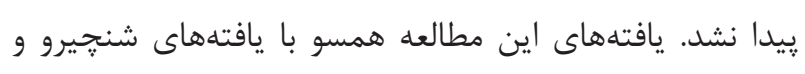

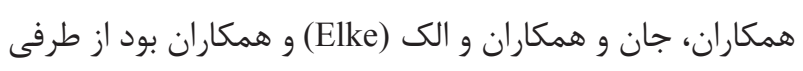

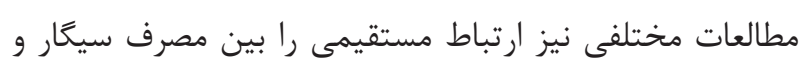

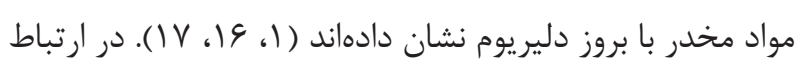
با سابقهى بيمارى روانى و بروز دليريوم در اين مطالعه ارتباط

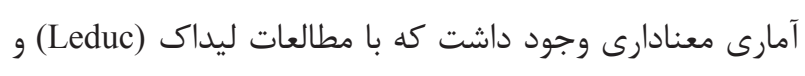

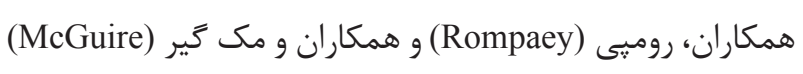

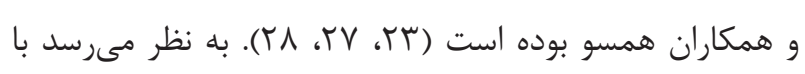
توجه به شرايط فرهنگى كشور و عدم يذيرش عمومى در ارتباط

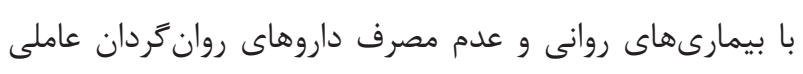

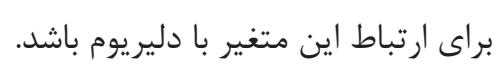

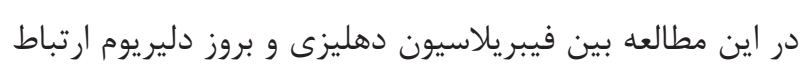

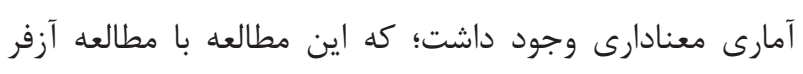
(Azfar)

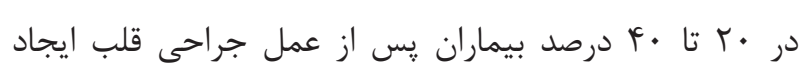

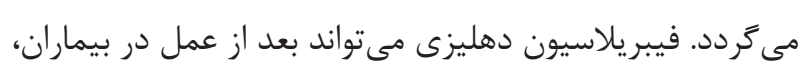
با كم كردن حداقل ها د درصد برون ده قلبى، خونر سانى به اندامها به خصوص مغز را با مشكل مواجه كند. از طرفى در اين بيماران

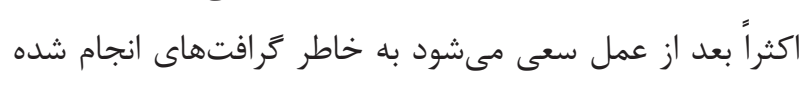

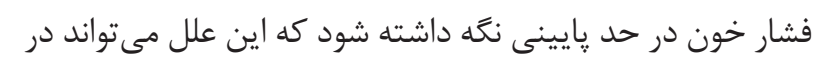
ارتباط اين متغير با دلير يوم نقش داشته باشند. در ارتباط با ميزان
مردان در اين مطالعه باشد. از نظر آمارى ارتباط معنى دارى بين

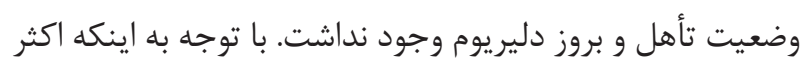

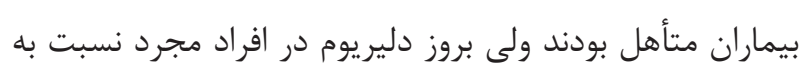

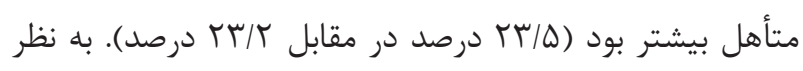

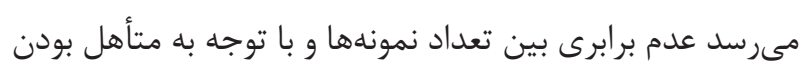

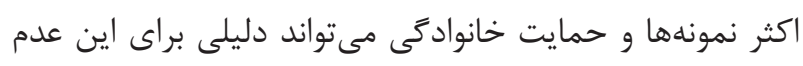
معنادارى باشد.

از نظر آمارى بين سطح درآمد و بروز دليريوم در اين مطالعه

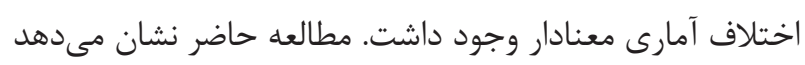

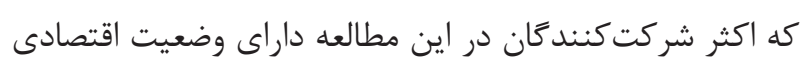

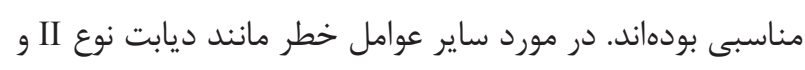

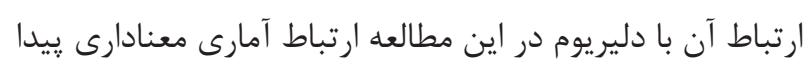

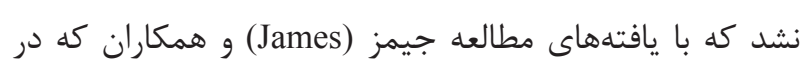

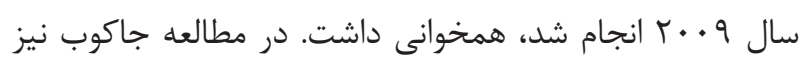

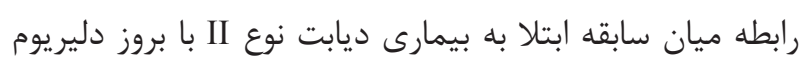

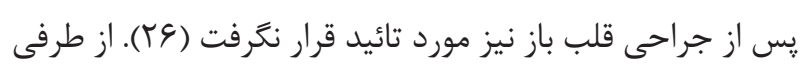

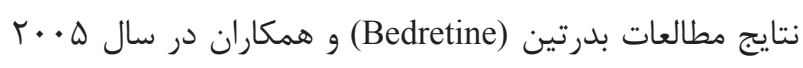

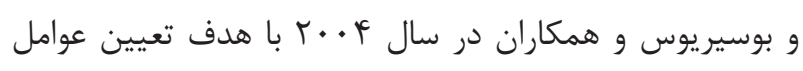

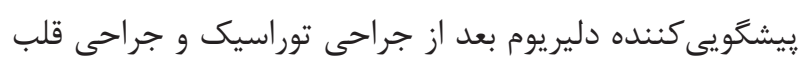

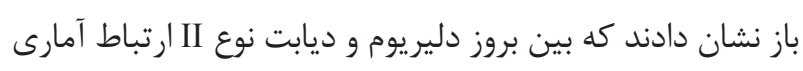
معنى دار وجود داشت (9 (1). به نظر مى برسد در اين مطالعه كنترل

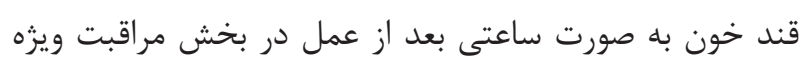

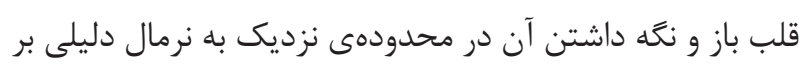
عدم معنادارى بين ديابت نوع دو و دليريوم باشد.

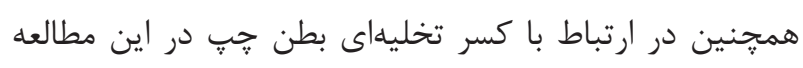

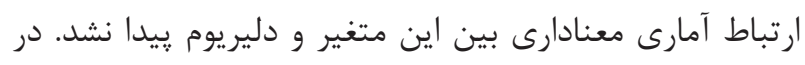

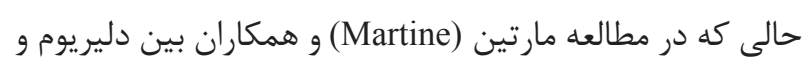
كسر تخليهاى بطن جֶٍ ارتباط آمارى معنادارى وجود داشت. به ماله نظر مىرسد در اين مطالعه اكثر نمونهها داراى كسر تخليهاى بطن

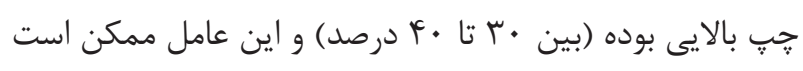

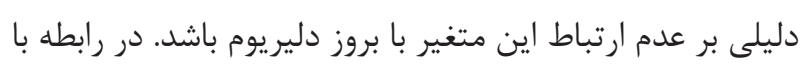

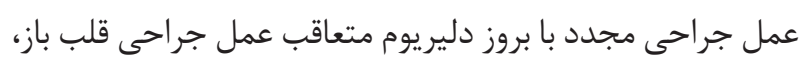

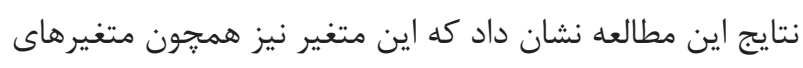

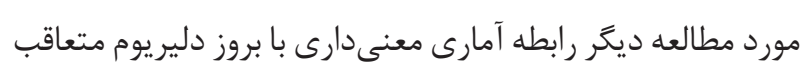




$$
\begin{aligned}
& \text { تشكر و قدردانى } \\
& \text { اين مقاله حاصل پايان نامه تحت عنوان "بررسى عوامل خطر مرتبط } \\
& \text { با دليريوم متعاقب عمل جراحى قلب باز در مراكز درمانى منتخب }
\end{aligned}
$$

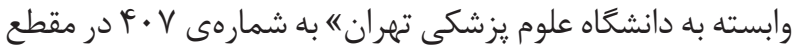

$$
\begin{aligned}
& \text { كارشناسى ارشد در سال 91\% } \\
& \text { علوم يزشكى و خدمات بهداشتى درمانى تهران اجرا شده است. } \\
& \text { بدين وسيله يثوهشگران از تمامى بيماران، همكاران و مسئولان } \\
& \text { محترم بيمارستانهاى مورد مطالعه كه ما را در انجام اين تحقيق } \\
& \text { يارى كردند، تشكر و سياسگزارى مىنمايند. }
\end{aligned}
$$

\section{References}

1- Rezaee F. [Translation of Psychiatry Abstract, Behavioral Sciences]. Kaplan H, Sadock V. Tehran: Arjmand Publication. 2008; 405-42. (Persian)

2- Chang Y, Tsai F, Lin P, Chen M, Liu C. Prevalence and risk factors for postoperative delirium in a cardiovascular intensive care unit. American journal of critical care 2008: 567-575.

3- Finkelmeier AB. Cardiothoracic surgical nursing. New York: Philadelphia; 2000.

4- Bucerius J, Gummert JF, Borger AM, Walther T, Doll N, Falk V, et al. Predictors of delirium after cardiac surgery delirium: Effect of beating-heart (off-pump) surgery. The Journal of Thoracic and Cardiovascular Surgery. 2004; 127: 57-64.

5- Bilotta F, Doronzio A, Stazi E, Titi L, Zeppa IO, Cianchi A, et al. Early postoperative cognitive dysfunction and postoperative delirium after anesthesia with various hypnotics: Study protocol for a randomized controlled trial - The Pinocchio trial Trials. 2011; 12: $170-7$.

6- Girard TD, Jackson JC, Pandharipande PP, Pun BT, Thompson JL, Shintani AK, et al. Delirium as a predictor of long-term cognitive impairment in survivors of critical illness.J Crit Care Med. 2010;38 (7): 1513-20

7- Akechi T, Okuyama T, Sagawa R, Furukawa TA. Delirium Training Program for Nurses. Psychosomatics. 2001; 51: 106-11.

8- Cerejeira J, Mukaetova-Ladinska EB. A Clinical Update on Delirium: From Early Recognition to EffectiveManagement. Nurs Res Pract. 2011; 1-12.

9- Page VJ, Navarange S, Gama S, McAuley DF. Routine delirium monitoring in a UK critical care unit. Crit Care. 2009; 13: 1-6.

10- Luukkanen M, Uusvaara J, Laurila J, Strandberg T, Raivio M, Tilvis R, et al. Anticholinergic drugs and their effects on delirium and mortality in the elderly. Dement GeriatrCogn Dis Extra. 2011; 1: 43-50.

11- Rudolph JL, Inouye S, Jones RN, Yang FM, Fong TG, Levkoff SE, etal. Delirium: An Independent Predictor of Functional Decline after Cardiac Surgery. J Am SocGeriatr. 2010; 58 (4): 643-9.

$$
\begin{aligned}
& \text { هماتوكريت با بروز دليريوم در اين مطالعه ارتباط آمارى معنادارى } \\
& \text { وجود داشت. از محدوديتهاى مطالعه مىتوان به اين مورد اشاره } \\
& \text { كرد كه با توجه به اينكه دليريوم يك بيمارى نوسان دار در طول } \\
& \text { شبانهروز مىباشد، اين امكان وجود داشت كه در بعضى از موارد } \\
& \text { علائم دليريوم در بين بررسىها بروز نموده و شناسايى نخردد. } \\
& \text { بر اساس نتايج مطالعه عواملى مانند سطح درآمد، بيمارى روانى، } \\
& \text { فيبريلاسيون دهليزى و ميزان هماتوكريت با بروز دليريوم مرتبط }
\end{aligned}
$$

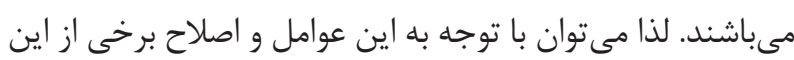

$$
\begin{aligned}
& \text { عوامل بعد از عمل جراحى بروز دليريوم كاهش داد. }
\end{aligned}
$$

12- Sockalingam S, Parekh N, Bogoch II, Sun J, Mahtani R, Beach C, et al. Delirium in the Postoperative Cardiac Patient: A Review. J Card Surg. 2005; 20: 560-7.

13- Flagg B, Cox L, Owell S, Mwose J, Buelow J. Nursing Identification of Delirium. ClinNurs Spec. 2010; 24 (5): 260-6.

14- George C, Nair JS, Ebenezer JA, Gangadharan A, ChristuDas A, Gnanaseelan LK. Validation of the Intensive Care Delirium Screening Checklist in nonintubated intensive care unit patients in a resource-poor medical intensive care setting in South India. Crit Care. 2011; 26: 138-43.

15- Ghanavati A, Forooghi M, Esmaeeli S, Hasantash A, Boloorian A, Shahzamani M. [Detecting of intraoprativeriskfactors in cardiac surgery].Journal of Iran Surgery. 2008; 17 (3): 1-10. [Article in Persian]

16- Deiner S, Silverstein J. Postoperative delirium and cognitive dysfunction. British J Anaesthesia. 2009; 103 (1): 41-6.

17- Kazmierski J, Kowman M, Banach M, Fendler W, Okonski P, BanysA,et al. Incidence and predictors of delirium after cardiac surgery: Results from The IPDACS Study. J Psychosomatic Research. 2010; 69: 179-85.

18- Bush SH, Bruer E. The Assessment and Management of Delirium in Cancer Patients. Oncologist. 2009; 14: 1039-49.

19- Finkelmeier AB. Cardiothoracic surgical nursing. NewYorc: Philadelphia; 2000.

20- Sotiris C, Stamou P, George D, Albert J. Stroke after coronary artey bypass. American stroke association. 2001; 32: 1508-1513.

21- Shinichiro M, Kenji Y, Norikazu M. Risk factors of stroke and delirium after off- pump coronary artery bypass grafting. Intensive cardiovascular and thoracic surgery. 2010, 56: 2278-2284

22- Inouye S, Carpenter P. Precipitating factors for delirium in hospitalized elderly persons. JAMA. 1996; 275: 852-857.

23- Holroyd-Leduc JM, Khandwala F, Kaycee M. How can delirium best be prevented and managed inolder patients in hospital? J Can Med Association. 2010; 182 (5): 465-70.

24- Taban H, AhmadZadeh GH, Tavasoli MH. [Pre and Post oprative 
cognitive disorder in geriatric surgery]. Journal of Hormozgan Medicine. 2001; 7 (3): 135-9. [Article in Persian]

25- Norkienė I, Samalavičius R, Misiūrienė I, Paulauskienė K, Budrys $\mathrm{V}$, Ivaškevičius J. Incidence and risk factors for early postoperative cognitive decline after coronary artery bypass grafting. J Medicina (Kaunas). 2010; 46 (7): 460-4

26- James L, Rudolph M, Viken L. Atherosclerosis is associated with delirium after coronary artery bypass graft surgery. JAGS.2005, 53: 462-426.

27- Rompaey BV, Elseviers MM, Chuurmans MJ, Shortridge-Baggett LM, Truijen S, Bossaert L. Risk factors for delirium in intensive care patients: a prospective cohort study. J Crit Care Med. 2009; 13: $1-12$.

28- McGuire JM, Burkard JF. Risk Factors for Emergence Delirium in U.S. Military Members. J PeriAnest Nursing. 2010; 25 (6): $392-$ 401.

29- Azfar G. Zaman RAA, Gérard Helft, Elizabeth A. Paul, Nicholas P. Curzen. Atrial Fibrillation after Coronary Artery Bypass Surgery: American Heart Association. 2014: 1403-8.

30- Michel Elie M, Martin G. Cole, MD, François J. Primeau, MD, François Bellavance, $\mathrm{PhD}$. Delirium Risk Factors in Elderly Hospitalized Patients. J GEN INTERN MED. 1998; 13: 204-12. 


\title{
The assessment of risk factors related to delirium after coronary by-pass graft
}

\author{
*Rad. $\mathrm{M}^{1}$, Nooredin. $\mathrm{M}^{2}$, Syedoshohdaee. $\mathrm{M}^{3}$, Haghani. $\mathrm{H}^{4}$, Assarzadeh. $\mathrm{S}^{5}$
}

\begin{abstract}
Introduction: Delirium is a syndrome characterized by impaired consciousness and changes in cognition. Which lots of patients after coronary by-pass graft have several neurological complications, This study aimed to recognize some risk factors related to delirium in patient who had a by- pass operation.

Materials and Methods: this cross-sectional study was conducted on 370 patients ranging from 18 to 85 years old and hospitalized in intensive care unit after coronary artery bypass graft surgery. Risk factors assessed including demographic variables, Diabetes Mellitus, drug abuse and smoking, hypertension, history of stroke and previous surgery, hematocrit lower than 30 percent, psychological disease. The convenience sampling method was used. After ending surgery and the separation from mechanical ventilation, the patients' mental status was daily examined by means of observational Delirium Screening Scale until they were discharged and transferred from ICU to the surgical ward.

Results: The incidence of delirium is reported $23 \%$. There is a significant relation between the incidence of delirium and variables such as atrial fibrillation, psychological disease, Income level and range of hematocrit.

Discussion and Conclusion: According to the results, screening and diagnosis of delirium after cardiac surgery is very important. With attention to individual profile and postoperative factors related to delirium, it is necessary to train about economic condition, product of blood and corrects this, underlying disease in order to decrease of delirium.
\end{abstract}

Keywords: Coronary artery bypass graft, Delirium, Risk factors.

1- ( ${ }^{*}$ Corresponding author) Msc in Critical Care Nursing, Iran, sabzeva, sabzevar University of Medical Sciences, Faculty of Nursing and Midwiferyr, Medical-Surgical Department. Email: Rad.mojtaba89@yahoo.com

2- PhD in Nursing, Iran, Tehran, Tehran University of Medical Sciences, Faculty of Nursing and Midwifery, Medical-Surgical Department

3- Msc in Nursing, Iran, Tehran, Tehran University of Medical Sciences, Faculty of Nursing and Midwifery, Medical-Surgical Department

4- Msc in Statistics Biostatistics, Iran, Tehran, Tehran University of Medical Sciences, Faculty of Nursing and Midwifery, Biostatistics Department

5- Bsc in Nursing, Instructor, Iran, sabzeva, sabzevar University of Medical Sciences, Faculty of Nursing and Midwifery, Medical-Surgical Department 